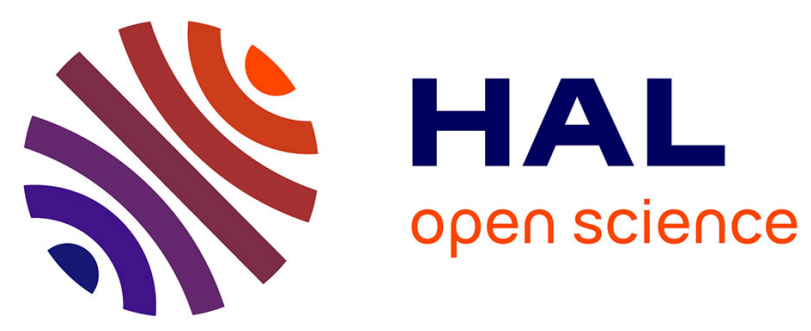

\title{
Colloidal transport of lipid digesta in human and porcine small intestinal mucus
}

Adam Macierzanka, Olivia Ménard, Didier Dupont, Krzysztof Gutkowski, Robert Staroń, Lukasz Krupa

\section{To cite this version:}

Adam Macierzanka, Olivia Ménard, Didier Dupont, Krzysztof Gutkowski, Robert Staroń, et al.. Colloidal transport of lipid digesta in human and porcine small intestinal mucus. Food Research International, 2020, 138, pp.109752. 10.1016/j.foodres.2020.109752 . hal-02975840

\section{HAL Id: hal-02975840 \\ https://hal.inrae.fr/hal-02975840}

Submitted on 23 Oct 2020

HAL is a multi-disciplinary open access archive for the deposit and dissemination of scientific research documents, whether they are published or not. The documents may come from teaching and research institutions in France or abroad, or from public or private research centers.
L'archive ouverte pluridisciplinaire HAL, est destinée au dépôt et à la diffusion de documents scientifiques de niveau recherche, publiés ou non, émanant des établissements d'enseignement et de recherche français ou étrangers, des laboratoires publics ou privés.

\section{(ㅇ)(1) $\$$}

Distributed under a Creative Commons Attribution - NonCommercial - NoDerivatives| 4.0 


\title{
Colloidal transport of lipid digesta in human and porcine small intestinal mucus
}

\author{
Adam Macierzanka a,b,c,*, Olivia Ménard ${ }^{\mathrm{d}}$, Didier Dupont ${ }^{\mathrm{d}}$, Krzysztof Gutkowski ${ }^{\mathrm{e}}$, \\ Robert Staroń $^{\mathrm{e}}$, Lukasz Krupa ${ }^{\mathrm{e}}$ \\ ${ }^{a}$ Gdańsk University of Technology, Faculty of Chemistry, Department of Colloid and Lipid Sciences, Gabriela Narutowicza 11/12, 80-322 Gdańsk, Poland \\ ${ }^{\mathrm{b}}$ Riddet Institute, Massey University, Private Bag 11 222, Palmerston North 4442, New Zealand \\ ${ }^{\mathrm{c}}$ Institute of Food Research, Norwich Research Park, Colney Lane, Norwich NR4 7UA, United Kingdom \\ d STLO, INRAE, Institut Agro, 65 Rue de St. Brieuc, 35042 Rennes, France \\ e Teaching Hospital No 1, Department of Gastroenterology and Hepatology with Internal Disease Unit, Chopina 2, 35-055 Rzeszów, Poland
}

\section{A R T I C L E I N F O}

\section{Keywords:}

Nutrient transport

Dynamic digestion model

Mucus barrier

Lipolysis

Proteolysis

Particle diffusion

\begin{abstract}
A B S T R A C T
Small intestinal mucus transport of food-derived particulates has not been extensively studied, despite mucus being a barrier nutrients need to cross before absorption. We used complex dispersions of digesta obtained from simulated, dynamic gastrointestinal digestion of yogurt to examine the penetrability of human and porcine mucus to the particles formed of lipolysis products. Quantitative, time-lapse confocal microscopy revealed a sieve-like behaviour of the pig jejunal and ileal mucus. The digesta diffusivity decreased significantly over the first $30 \mathrm{~min}$ of mucus penetration, and then remained constant at ca. $5 \times 10^{-12} \mathrm{~m}^{2} \mathrm{~s}^{-1}$ (approx. $70 \%$ decrease from initial values). A non-significantly different penetrability was recorded for the ileal mucus of adult humans. The digesta diffusion rates in neonatal, jejunal mucus of 2 week old piglets were 5-8 times higher than in the three different types of adult mucus. This is the first report that validates the mucus of fully-grown pigs as a human-relevant substitute for mucus permeation studies of nutrients/bio-actives and/or complex colloidal dispersions (e.g., post-digestion food particulates, orally-administrated delivery systems).
\end{abstract}

\section{Introduction}

The small intestine is the part of the alimentary tract where most of food digestion and nutrient absorption take place. In order to get absorbed by the body, any nutrients released from food during digestion in the intestinal lumen need to penetrate through the mucus layer that separates the underlying epithelium from luminal contents (Johansson, Sjövall, \& Hansson, 2013). The mucus layer is a selective barrier. It allows the passage of molecules (e.g., water-soluble nutrients, bioactives, pharmaceuticals, etc.) and small particles (e.g., lipid/bile salt mixed micelles, etc.), but prevents the epithelium from direct exposure to luminal microorganisms, including pathogens (Cone, 2009). It also lubricates the mucosal epithelium, which is crucial in protecting the tissue from abrasions that can be caused by the peristaltic movement of luminal contents.
The small intestinal mucus is a viscoelastic hydrogel made from a number of components, amongst which the MUC2 mucin glycoprotein is the major gel-forming macromolecule responsible for the porous structure and rheological properties of the mucus (Corfield, Carroll, Myerscough, \& Probert, 2001; Round et al., 2012). Several studies have also pointed out at the importance of extracellular DNA in maintaining the microstructural organisation and high viscosity of the mucus as well as its barrier properties with regard to penetrability to particles and bacteria (Lock et al., 2020; Macierzanka et al., 2014).

Despite the importance of small intestinal mucus in regulating the access of nutrients to the epithelium, there is a limited number of studies looking at the penetrability of the mucus layer by digested food. So far, most of the research in this area has either focused on monitoring the local diffusivity of molecules (e.g., polyphenols, alginates) inside the mucus matrix (Gonzales et al., 2015; Mackie, Macierzanka, et al., 2016),

Abbreviations: CLSM, confocal laser scanning microscopy; D, diffusion coefficient; DG, diglyceride; FFA, free fatty acid; GI, gastrointestinal; MG, monoglyceride; TG, triglyceride.

* Corresponding author at: Gdańsk University of Technology, Faculty of Chemistry, Department of Colloid and Lipid Sciences, Gabriela Narutowicza 11/12, 80-322 Gdańsk, Poland.

E-mail address: adam.macierzanka@pg.edu.pl (A. Macierzanka). 
or on characterising the mucus structure by a combination of qualitative and quantitative microscopy methods, often with the use of synthetic particles simulating digesta. In the latter case, one of regularly used methods is multiple-particle tracking (MPT), which relies on simultaneous real-time monitoring of the displacement of hundreds or thousands of individual particles (Lai, Wang, Wirtz, \& Hanes, 2009). Evaluation of the diffusivity of identical-in-size nano- or micro-particles allows for probing the permeability, microrheology, and heterogeneity in microstructural organisation of mucus (Lai, Wang, Hida, Cone, \& Hanes, 2010; Lock et al., 2020; Macierzanka, Mackie, \& Krupa, 2019). This method has been used to determine the role of the size and surface chemistry of particles on their transport in mucus (Maisel, Ensign, Reddy, Cone, \& Hanes, 2015; Yildiz, McKelvey, Marsac, \& Carrier, 2015). For instance, it was shown that a high negative charge of the surface of polystyrene beads, caused by adsorption of anionic intestinal surfactants - bile salts (BS), significantly enhanced the ability of the beads to diffuse in the small intestinal mucus (Macierzanka et al., 2011). It was suggested this was due to the BS adsorption preventing mucoadhesion of the beads to the negatively-charged mucus matrix. MPT has also been used to assess the intestinal mucus diffusion of postdigestion emulsion droplets (i.e., the droplets obtained after in vitro gastro-duodenal proteolysis of protein-stabilised oil-in-water emulsions (Macierzanka et al., 2011, 2012)). However, these measurements were only conducted using size-narrowed monomodal fractions of droplets with well-defined diameters. Whilst monitoring the diffusion of spherical particles with known, uniform sizes does allow for calculating microrheological parameters of the mucus, the application of such particles can be of limited physiological relevance, as gastrointestinal (GI) digestion of food emulsions usually yields a broad distribution of particles in the gut lumen - from nano-size mixed micelles of bile salts and the lipolysis products to larger, micro-size droplets of partially digested lipids (Armand et al., 1999). Under physiological conditions of the small intestine, it is these complex dispersions of food-derived particles that interact simultaneously with the mucus layer. Therefore, studies looking at the intestinal bioaccessibility and transport rates of nutrients should use such physiologically relevant dispersions.

Another potential limitation of most scientific studies that have been conducted over the recent years in this area is that they used animal mucus, usually obtained from mice, rats or pigs, to simulate a difficultto-obtain human mucus. Even for porcine mucus, its human-relevance cannot be assumed without scientific validation, despite the human GI physiology being historically considered most similar to that of pigs (Zhang, Widmer, \& Tzipori, 2013). This might be especially true for studying interactions with digesta produced from real foods, where colloidal complexity of such dispersions can highlight even small differences in microstructural organisation and penetrability of the human mucus relative to mucus of animal origin.

This study had more than one goal. Firstly, we used digesta samples obtained from semi-liquid food emulsion (natural yogurt was used), following different digestion times, to look at their ability to penetrate the small intestinal mucus and whether the transport characteristics change in time. By investigating this, we also intended to give an example of how in vitro digestion models can be complemented with simulating the passive transport of nutrients/particles through the mucus layer under intestinal conditions. Secondly, we wanted to compare the permeability of porcine and human small intestinal mucus to complex digesta produced from real food. This aimed to examine the hypothesis of a similar barrier function of the porcine and human mucus, and, if confirmed, would validate the use of porcine mucus for future investigations on the mucus transport of post-digestion food particulates under simulated human small intestinal conditions.

\section{Materials and methods}

\subsection{Human small intestinal mucus}

The collection and studies of the human small intestinal mucus were approved by the ethics committee of the Regional Medical Chamber in Rzeszów, Poland (certificate no. 4/B/2015). All methods were planned and conducted in accordance with the ethical principles outlined in the Declaration of Helsinki. Aspiration of mucus from the terminal ileum was done during diagnostic colonoscopy performed at the Teaching Hospital No 1 in Rzeszów. The procedure duration was extended for a maximum of 5 min to obtain mucus samples. A typical indication for colonoscopy was either occasional lower-GI bleeding, persistent unexplained abdominal pain, or screening and surveillance of colorectal polyps, and 51 individuals ( 31 men and 20 women), aged 34-67 years, were initially included in the study. Any evidence of inflammatory changes to the mucosa of the colon and/or the terminal ileum confirmed during the procedure disqualified a subject from the study. All individuals who agreed to take part in the study were clearly informed about the procedure and instructed by a clinician regarding the bowel preparation. Informed consent was provided by all participants prior to examination. Personal information of the volunteers was de-identified.

All participants included in the study followed a low residue diet protocol for 5 days prior to colonoscopy in order to improve bowel preparation. Individuals listed for colonoscopy received bowel prepa-

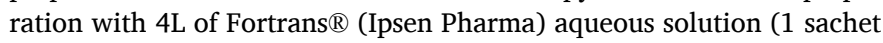
dissolved in $1 \mathrm{~L}$ of water). One sachet of Fortrans ${ }^{\circledR}$ powder contained Macrogol 4000 (64 g), anhydrous sodium sulphate (5.7 g), sodium bicarbonate $(1.68 \mathrm{~g})$, sodium chloride $(1.46 \mathrm{~g})$, and potassium chloride $(0.75 \mathrm{~g})$. The timing of bowel preparation prior to colonoscopy has a very significant impact on the preparation quality. It has been reported that the optimal time for the colonoscopy procedure after completion of bowel preparation is $3-4 \mathrm{~h}$, and should be less than $8 \mathrm{~h}$ after completion of the preparation (Seo et al., 2012). This concept has led to a split-dose preparation, which requires taking a portion of the bowel preparation solution the night prior to colonoscopy ( $50 \%$ of the total dose) and the remaining portion on the day of colonoscopy (Bucci et al., 2014). The split-dose preparation was used in this study. The participants received 2 sachets of Fortrans ${ }^{\circledR}$ diluted in $2 \mathrm{~L}$ of water between 6:00-8:00 pm on the day before colonoscopy and the remaining $2 \mathrm{~L}$ of solution between 5:00-6:00 am on the day of the procedure.

As a routine part of colonoscopy examination, the intubation of the terminal ileum is performed (Meral et al., 2018). This part of the small bowel contains a relatively thin layer of the mucus which is distributed on the mucosal surface of the bowel wall. We only performed aspiration of the mucus samples from the terminal ileum in participants who had bowel preparation rated as excellent (i.e., rate 9 of the Boston Scale (Lai, Calderwood, Doros, Fix, \& Jacobson, 2009)). Once the terminal ileum was intubated with the colonoscope, the mucosal layer was inspected and an optimal area for aspiration of mucus chosen (i.e., an area free of residual liquid, etc.). At the same time, an assistant endoscopist inserted a disposable plastic catheter through the biopsy channel of the colonoscope. While inserting the catheter, air was being constantly insufflated with a syringe attached to one end of the catheter in order to prevent incidental aspiration of any material that might have resided in the biopsy channel and would potentially lead to the contamination of a sample. Once the catheter was in the lumen of the terminal ileum, the principal endoscopist was in charge of the control of the colonoscope tip and the catheter. The assistant endoscopist performed aspiration of the mucus by applying a gentle suction with a syringe. Mucus was only aspirated into the tip of the catheter in order to limit disturbing of the sampled mucus, and from the mucosal surface of the terminal ileum located between $5 \mathrm{~cm}$ and $25 \mathrm{~cm}$ from the ileocecal valve. Typically, no more than $0.5 \mathrm{~mL}$ mucus was aspirated from one subject over the limited time that was allowed for mucus collection. Immediately after aspiration, the plastic catheter was removed and the sample gently transferred 
into $0.5 \mathrm{~mL}$ plastic test tubes. The tubes were sealed and instantly immersed in liquid nitrogen for snap freezing. Samples were stored at $-80^{\circ} \mathrm{C}$ prior to further examination.

Mucus samples collected from five individuals (three women and two men; 51-56 years old) were used in the experiments described below in order to narrow down the age range of adult humans.

\subsection{Porcine small intestinal mucus}

The collection of porcine mucus, including the ex vivo handling of intestinal tissue, was done as described previously (Macierzanka et al., 2014; Macierzanka, Mackie, et al., 2019). In brief, mucus was gently removed with a soft-rubber scraper from the mucosal surface of freshly excised and cleaned small intestines of (i) 6-8-month old pigs (this being referred to as the 'adult pig mucus' or the 'mucus from fully-grown pigs' throughout the paper) and (ii) 2 week old piglets (this being referred to as the 'piglet mucus'). Pig mucus was collected from the most proximal, 1-meter-long jejunal segment and/or the most distal, 1-metre-long ileal segment. The last $5 \mathrm{~cm}$ of the ileum before the ileocecal valve was discarded. Piglet mucus was only collected from the most proximal jejunum (0.5-0.7-meter-long segment). Aliquots of collected mucus were immediately transferred to $0.5 \mathrm{~mL}$ plastic screw-cap tubes for snap freezing in liquid nitrogen, and then stored at $-80^{\circ} \mathrm{C}$. The collection was carried out within $20 \mathrm{~min}$ from animal slaughter. Mucus was incubated for $10 \mathrm{~min}$ at RT before use. As reported previously (Macierzanka et al., 2011; Macierzanka, Mackie, et al., 2019), the freezing, storing and thawing cause no significant differences in the macro- and microrheological properties of small intestinal mucus.

\subsection{Yogurt in vitro dynamic digestion and characterisation of digesta samples}

A commercially available, natural yogurt ( $\mathrm{pH} 4.2)$ was used. The yogurt was obtained from cow's milk and contained $3.5 \mathrm{wt} \%$ fat, $4.5 \mathrm{wt}$ $\%$ protein and $6.6 \mathrm{wt} \%$ carbohydrates, according to the information provided by the producer (Danone). The yogurt ( $120 \mathrm{~g}$ ) was put through the dynamic in vitro gastrointestinal digestion simulator DIDGI ${ }^{\circledR}$ (Fig. 1A, (Ménard et al., 2014)), mimicking the adult human gastric and small intestinal conditions. The digestion was done in triplicate, following the procedure described before (Ménard, Famelart, et al., 2018), with some modifications. The specific gastrointestinal digestion parameters applied have been summarised in Table 1 . The flow of enzyme secretions, prepared with either simulated gastric fluid (SGF) or simulated intestinal fluid (SIF; Table 1), as well as the emptying rates and $\mathrm{pH}$, were continuously monitored using the STORM ${ }^{\circledR}$ software of the DIDGI ${ }^{\circledR}$ system (INRAE, France). Gastric and intestinal emptying rates followed an exponential equation as described by (Elashoff, Reedy, \& Meyer, 1982). The gastric and intestinal half-times $\left(\mathrm{t}_{1 / 2}\right)$ of $70 \mathrm{~min}$ and $160 \mathrm{~min}$, respectively, and $\beta$ coefficient of 2 and 1.6, respectively, were applied according to the values reported by Minekus, Marteau, Havenaar, and Huisintveld (1995) for yoghurt digestion in adults. A gastric acidification curve was obtained after modelling data from adult humans (Malagelada, Longstreth, Summerskill, \& Go, 1976). Evolutions in the volumes of gastric and small intestinal contents, as well as in $\mathrm{pH}$ values, have been shown in Supplementary Figs. S1 and S2. In the gastric compartment of digestion, porcine pepsin (Sigma-Aldrich, P6887) was used at $2000 \mathrm{U} / \mathrm{mL}$ of gastric content (Minekus et al., 2014), and lipase
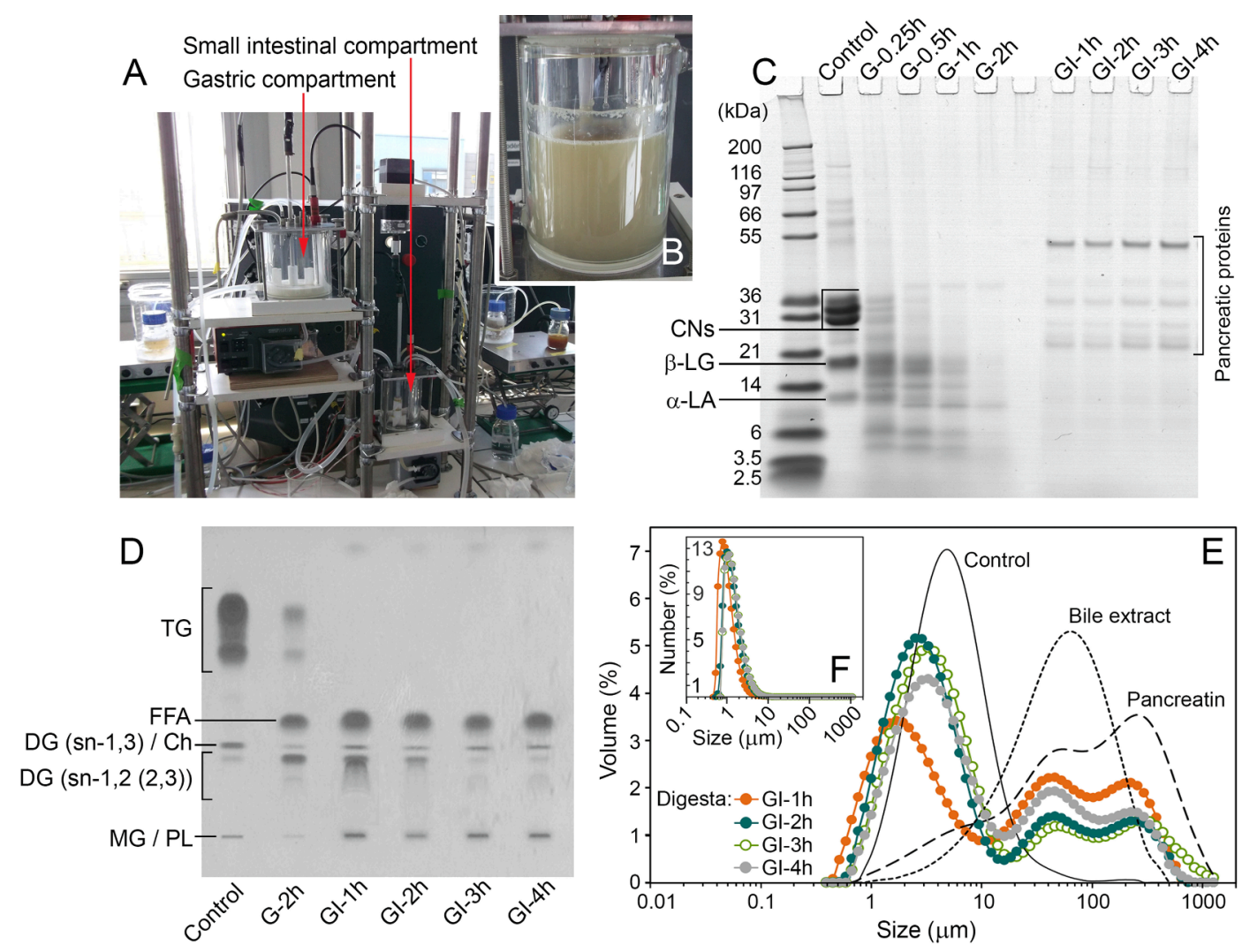

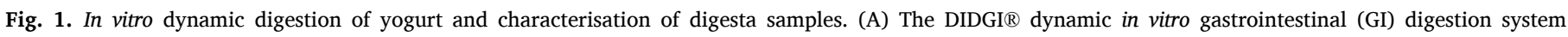

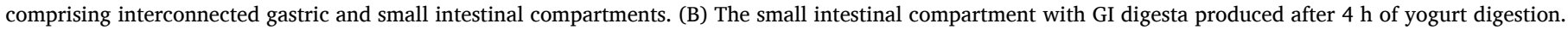

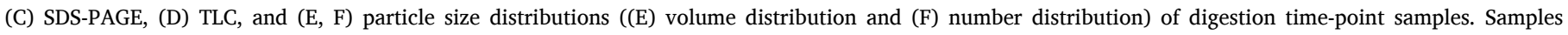

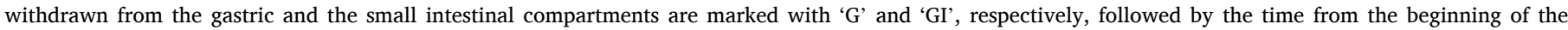

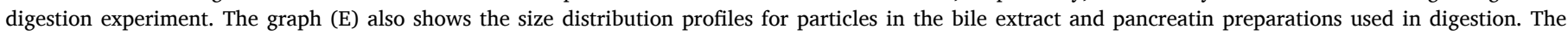

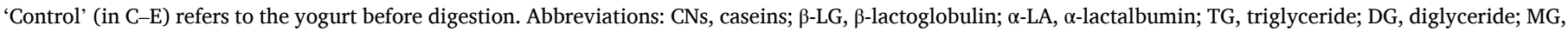
monoglyceride; PL, phospholipid; Ch, cholesterol; FFA, free fatty acid. 
Table 1

Gastrointestinal parameters of in vitro dynamic digestion of yogurt.

\begin{tabular}{|c|c|c|}
\hline \multicolumn{3}{|l|}{ Gastric conditions $\left(37^{\circ} \mathrm{C}\right)$} \\
\hline $\begin{array}{l}\text { Simulated Gastric Fluid } \\
\text { (SGF) } \\
\text { (stock solution adjusted } \\
\text { at pH 6.5) }\end{array}$ & $\begin{array}{l}\mathrm{Na}^{+} \\
\mathrm{Ca}^{2+}\end{array}$ & $\begin{array}{l}100 \mathrm{mmol} / \mathrm{L} \\
1 \mathrm{mmol} / \mathrm{L}\end{array}$ \\
\hline Yogurt & $\begin{array}{l}\text { Ingested } \\
\text { amount }\end{array}$ & $120 \mathrm{~g}$ \\
\hline $\begin{array}{l}\text { Gastric pH (acidification } \\
\text { curve) } \\
\text { (using } 1 \mathrm{M} \mathrm{HCl} \text { ) }\end{array}$ & \multicolumn{2}{|c|}{$\mathrm{pH}=1.68+3.82^{(-\mathrm{t} / 42)}(t$, time after ingestion in min $)$} \\
\hline \multirow[t]{3}{*}{$\mathrm{SGF}+$ pepsin (porcine) } & Pepsin & $2000 \mathrm{U} / \mathrm{mL}$ of gastric content \\
\hline & Flow rate & $0.75 \mathrm{~mL} / \mathrm{min}$ from 0 to $10 \mathrm{~min}$ \\
\hline & Flow rate & $\begin{array}{l}0.25 \mathrm{~mL} / \mathrm{min} \text { from } 10 \mathrm{~min} \text { to the } \\
\text { end of the gastric phase }\end{array}$ \\
\hline \multirow[t]{3}{*}{ SGF + lipase (fungal) } & Lipase & $18 \mathrm{U} / \mathrm{mL}$ of gastric content \\
\hline & Flow rate & $0.75 \mathrm{~mL} / \mathrm{min}$ from 0 to $10 \mathrm{~min}$ \\
\hline & Flow rate & $\begin{array}{l}0.25 \mathrm{~mL} / \mathrm{min} \text { from } 10 \mathrm{~min} \text { to the } \\
\text { end of the gastric phase }\end{array}$ \\
\hline \multirow{2}{*}{$\begin{array}{l}\text { Gastric emptying } \\
\text { (Elashoff fitting) }\end{array}$} & $t_{1 / 2}$ & $70 \mathrm{~min}$ \\
\hline & $\beta$ & 2 \\
\hline \multicolumn{3}{|l|}{ Intestinal conditions $\left(37^{\circ} \mathrm{C}\right)$} \\
\hline $\begin{array}{l}\text { Simulated Intestinal Fluid } \\
\text { (SIF) } \\
\text { (stock solution adjusted } \\
\text { at pH 6.2) }\end{array}$ & $\begin{array}{l}\mathrm{Na}^{+} \\
\mathrm{Ca}^{2+}\end{array}$ & $\begin{array}{l}100 \mathrm{mmol} / \mathrm{L} \\
1 \mathrm{mmol} / \mathrm{L}\end{array}$ \\
\hline $\begin{array}{l}\text { Intestinal pH } \\
\text { (using } 1 \mathrm{M} \mathrm{NaHCO} \\
3 \text { ) }\end{array}$ & $\mathrm{pH}$ & 6.6 \\
\hline \multirow[t]{3}{*}{ SIF + bile extract (porcine) } & Bile & $4 \%$ from 0 to $30 \mathrm{~min}$ \\
\hline & Bile & $2 \%$ from $30 \mathrm{~min}$ to the end \\
\hline & Flow rate & $0.5 \mathrm{~mL} / \mathrm{min}$ from $0 \mathrm{~min}$ to the end \\
\hline \multirow[t]{2}{*}{ SIF + pancreatin (porcine) } & Pancreatin & $7 \%$ \\
\hline & Flow rate & $0.25 \mathrm{~mL} / \mathrm{min}$ from $0 \mathrm{~min}$ to the end \\
\hline \multirow{2}{*}{$\begin{array}{l}\text { Intestinal emptying } \\
\text { (Elashoff fitting) }\end{array}$} & $\mathrm{t}_{1 / 2}$ & $160 \mathrm{~min}$ \\
\hline & $\beta$ & 1.6 \\
\hline
\end{tabular}

A12 from Aspergillus niger (Amano) at $18 \mathrm{U} / \mathrm{mL}$ of gastric content. The intestinal conditions were set up as reported by Minekus et al. (1995), using pancreatin from porcine pancreas (Sigma-Aldrich, P7545) and porcine bile extract (Sigma-Aldrich, B8631). Intestinal $\mathrm{pH}$ was maintained at 6.6.

The gastrointestinal digestion was carried out continuously for $4.5 \mathrm{~h}$ at $37{ }^{\circ} \mathrm{C}$. Samples of digesta were taken periodically from the gastric compartment (after $0.25,0.5,1$, and $2 \mathrm{~h}$ from the beginning of the digestion procedure) and the intestinal compartment (after 1, 2, 3 and 4 $\mathrm{h}$ from the beginning of the procedure) and analysed using the methods described below. The enzymatic activity in digesta samples, that were withdrawn for subsequent analysis of the proteolysis progress, was immediately inhibited by using protease inhibitors, pepstatin A $(0.72$ $\mathrm{mM}$ ) for gastric samples and phenylmethanesulfonyl fluoride $(0.37 \mathrm{mg} /$ $\mathrm{mL}$; Sigma-Aldrich, 93482) for intestinal samples. The extent of proteolysis in digesta samples was assessed by SDS-PAGE using the procedure described elsewhere (Böttger et al., 2019; Ménard, Famelart, et al., 2018). The digesta samples that were used in the mucus penetration experiments (Section 2.4) were additionally treated with Orlistat (Sigma-Aldrich, 04139) at the final concentration of $200 \mu \mathrm{M}$. Lipolysis in the digesta samples withdrawn for the purpose of analysing changes in the lipid profiles was inhibited by the addition of $0.1 \mathrm{M}$ 4-bromophenylboronic acid solution in methanol (Sigma-Aldrich, B75956; $50 \mu \mathrm{L}$ of solution per $1 \mathrm{~mL}$ of digesta). A direct extraction of lipids from digesta was performed after sampling, and was based on the Folch method (Ménard, Bourlieu, et al., 2018). Thin layer chromatography (TLC) was used to assess the overall lipid profiles of digesta samples, according to the method described previously (Ménard, Bourlieu, et al., 2018). The TLC allowed for monitoring the disappearance of triglycerides (TGs) present in the yogurt and the appearance of lipolysis products during digestion.

The particle size distribution of yogurt, digesta samples, as well as some dispersions of materials used in the digestion model (i.e., insoluble particles in the bile extract and pancreatin preparations) was obtained from dynamic light scattering (Mastersizer, 2000, Malvern Instruments, Malvern, UK) using the method described before (Ménard, Bourlieu, et al., 2018). Samples were measured either in their original state or after treatment with $0.5 \%(\mathrm{w} / \mathrm{v})$ sodium dodecyl sulfate (SDS) to evaluate the size distribution of deflocculated particles. The zeta-potential $(\zeta)$ of the gastrointestinal digesta samples was measured using the method described previously (Macierzanka et al., 2011, 2012). The gastrointestinal digesta samples were used in experiments looking at the diffusion of partially digested lipids through human and porcine small intestinal mucus.

\subsection{Diffusion of gastrointestinal digesta in human and porcine small intestinal mucus}

The ability of the gastrointestinal digesta (i.e., the digesta samples withdrawn from the intestinal compartment, after the yogurt had been exposed to the gastric followed by the small intestinal digestion for 1, 2, 3 and $4 \mathrm{~h}$, Fig. $1 \mathrm{~A}, \mathrm{~B}$ ) to penetrate into the mucus layer was assessed using time-lapse confocal laser scanning microscopy (CLSM). The mucus was stained for mucins with WGA-Oregon Green (Invitrogen, W6748; 1 $\mathrm{mg} / \mathrm{mL}$ in PBS buffer (Sigma-Aldrich, P4417), $\mathrm{pH} 7.4$, containing $2 \%$ $(\mathrm{w} / \mathrm{v})$ sodium azide). The mucus was gently mixed with the dye stock at a high mucus to stock ratio, 99: 1 (v/v), in order to minimise the dilution of mucus. This produced the final dye concentration of $10 \mu \mathrm{g} / \mathrm{mL}$ and sodium azide concentration of $0.02 \%(w / v)$ in mucus. Separately, the digesta was stained for lipids with Nile Red (Sigma-Aldrich, 72485) at a final dye concentration of $8 \mu \mathrm{g} / \mathrm{mL}$. The mucus was placed in a custommade optical cell developed for this study. The cell consisted of a chamber $(6 \times 6 \times 1 \mathrm{~mm})$ for mucus and an adjacent channel (luminal space) for introducing digesta (Fig. 2A). After the chamber was filled with mucus to $60-80 \%$ of its volume, the cell was covered with a coverslip, and the mucus boundary localised under the microscope. The cell with mucus was incubated on the microscope stage at $37 \pm 0.1{ }^{\circ} \mathrm{C}$ for 3 min. Subsequently, the liquid digesta (preconditioned at RT) was gently introduced through the channel inlet to the luminal space (Fig. 2A; ca. $100 \mu \mathrm{L}$ of digesta was required), and finally the channel sealed to prevent water evaporation during the experiment. This part of the procedure was done in less than $60 \mathrm{~s}$, which was sufficient to bring the temperature of the introduced digesta to ca. $37^{\circ} \mathrm{C}$. The introduction of digesta was done after the cell with mucus had been securely positioned on the microscope stage, in order to start monitoring the penetration of mucus with digesta immediately after the two components were brought into contact with each other. The transport progress was recorded at $37 \pm 0.1{ }^{\circ} \mathrm{C}$ with a Leica TCS SP upright confocal microscope (Leica Microsystems (UK) Ltd, UK). The penetration was followed for up to $90 \mathrm{~min}$, and assessed using a procedure adopted from a previous study (Mackie, Macierzanka, et al., 2016). Briefly, linear fluorescent intensity profiles of the Nile Red stained lipids in digesta were generated from the time-lapse images $(500 \times 500 \mu \mathrm{m}, 1024 \times 1024$ pixel, $30 \mathrm{~s}$ time intervals) using Image-Pro Analyzer 7.0 software (Media Cybernetics Inc., Silver Spring, MD, USA). The diffusion coefficient was calculated from the fluorescence profiles using the following equation, $F(x, t)=a \times e r f c$ $\left(x /(4 D t)^{1 / 2}\right)$, where $F$ is the fluorescence of digesta stained for lipids described as a function of distance from the starting boundary $x$ and time $t$. Here, $a$ is an arbitrary scalar, erfc is the complimentary error function and $D$ is the diffusion coefficient of the fluorescent lipids.

All experiments were performed for mucus samples obtained from 3 to 5 individual pigs, piglets or humans, and at least three times (i.e., for three separate mucus specimens) for each individual mucus source. Results are presented as the mean $\pm \mathrm{SD}$ and/or distributions of data from measurements, for each condition used. Statistical comparisons between two groups were made using a Student's $t$-test, and three (or more) groups were evaluated using 1-way ANOVA (significance level, $\alpha=$ 0.05). 

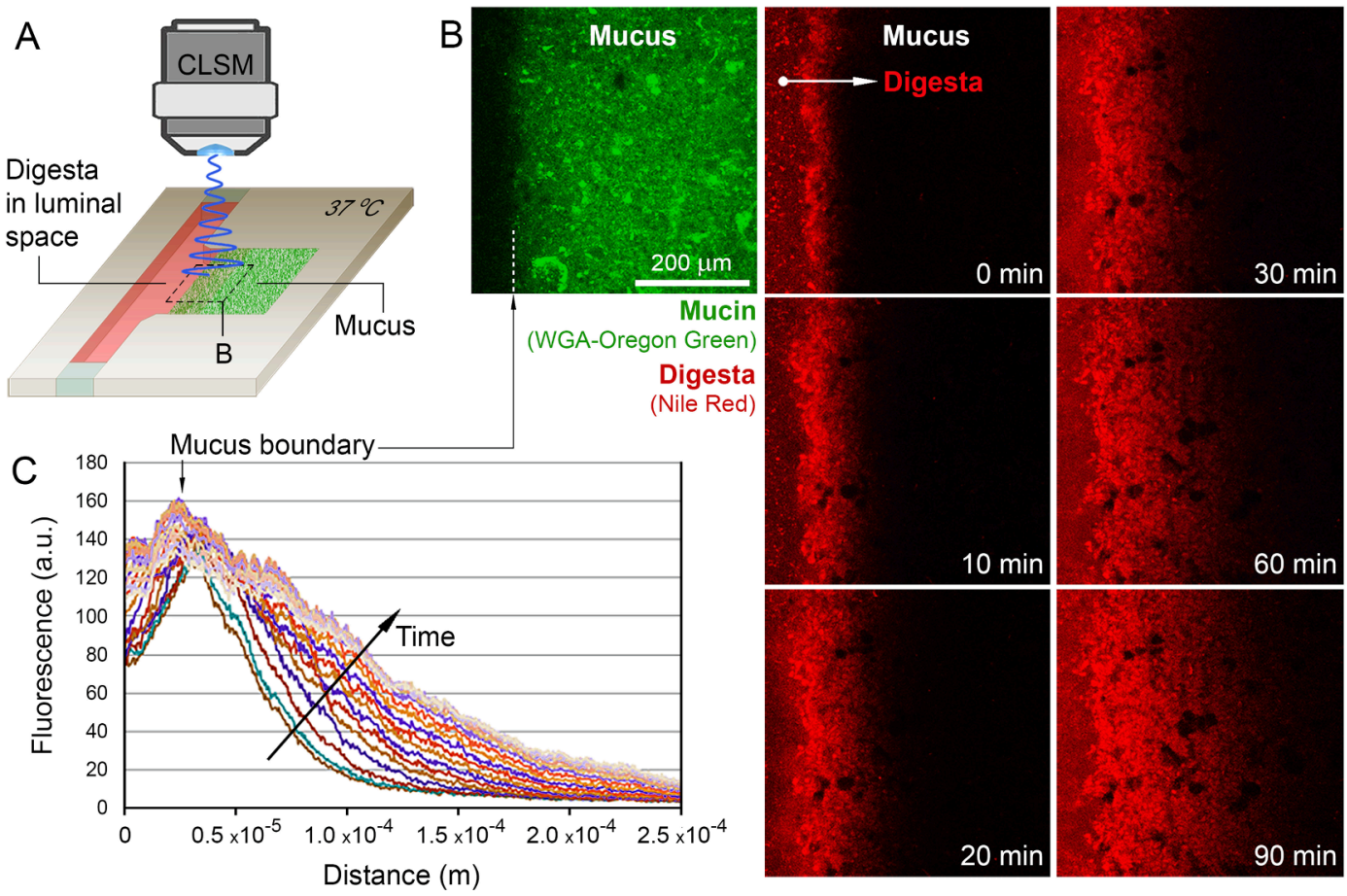

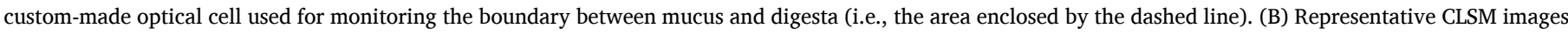

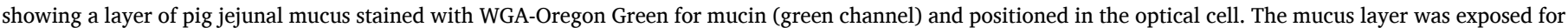

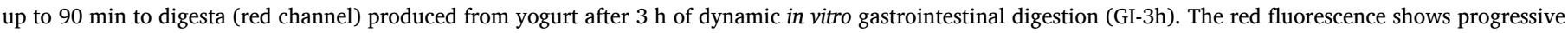

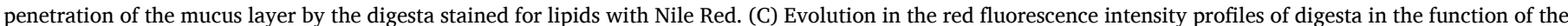

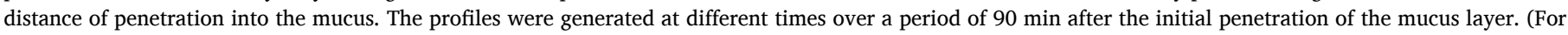
interpretation of the references to colour in this figure legend, the reader is referred to the web version of this article.)

\section{Results and discussion}

\subsection{Yogurt in vitro digesta}

The first step of the study was to obtain digesta from real food. Natural yogurt was selected as it is an example of a semi-liquid dairy product that is consumed worldwide and contains substantial quantities of all macronutrients. It was not the aim of this study to investigate in detail the gastrointestinal digestion of yogurt, but rather to produce in vitro a selection of liquid digesta samples that could be used to investigate the transport of partially digested food particulate matter through small intestinal mucus of various origins. The dynamic in vitro model of human gastrointestinal digestion was chosen to accurately mimic the digestive conditions in adult humans and to produce digesta.

Consequently, we have only carried out qualitative analyses of the proteolysis progress using SDS-PAGE (Fig. 1C). The protein bands corresponding to milk caseins showed a progressive and substantial reduction in intensity, which implied a rapid hydrolysis of the caseins by pepsin. After $0.5 \mathrm{~h}$ of gastric digestion, there were no casein bands observed. The pepsinolysis of whey proteins, $\beta$-lactoglobulin and $\alpha$-lactalbumin, seemed to be largely completed after $2 \mathrm{~h}$ of the gastric digestion. The in vitro gastrointestinal proteolysis of yogurt has been studied before. Ménard, Famelart, et al. (2018) reported on relatively quick gastric degradation of caseins in several isocaloric yogurts that differed in the original viscosity (0.3-2.2 $\mathrm{Pa}$ s) and milk protein content (3.1-8.1 wt\%). In that study, the amount of caseins in the yogurts was reduced to only $4 \mathrm{wt} \%$ of the original amount after $2 \mathrm{~h}$ of the simulated dynamic gastric digestion with pepsin. The amounts of residual $\beta$-lactoglobulin and $\alpha$-lactalbumin at the end of the gastric digestion were more dependent on the original protein concentration and yogurt viscosity. However, for conventional yogurt (i.e., with a total protein content of $3.1 \mathrm{wt} \%$; viscosity, $1.3 \mathrm{~Pa}$ s), $\beta$-lactoglobulin and $\alpha$-lactalbumin were reduced to only $3.1 \mathrm{wt} \%$ and $6.4 \mathrm{wt} \%$ of the original amounts, respectively. The digestion of both caseins and whey proteins was finalised in the intestinal compartment, and resulted in complete disappearance of the protein SDS-PAGE bands after $3 \mathrm{~h}$ of the dynamic gastrointestinal digestion. A similar, rapid proteolysis of caseins and whey proteins has been observed under static in vitro gastrointestinal conditions for yogurts prepared with different casein:whey protein ratios $(4.5: 1,2.8: 1$ and $1.5: 1$ ) and $3.70-3.75 \%$ total protein contents (Rioux \& Turgeon, 2012). For all those types of yogurt, the vast majority of the original amounts of caseins and whey proteins was hydrolysed during the gastric phase of digestion. Overall, the findings of the two studies described above are in good agreement with our results shown in Fig. 1C.

In the present study, we have also looked at changes in the lipid profile of the milk fat fraction of yogurt (Fig. 1D). Unsurprisingly, the TLC showed triglycerides (TGs) as a major lipid class in the yogurt before digestion. They were hydrolysed to some extent to free fatty acids (FFAs) and partial glycerides - di- and monoglycerides (DGs, MGs) during gastric digestion, and after $2 \mathrm{~h}$ TGs coexisted with the lipolysis products. The complete conversion of remaining TGs seemed to largely take place during the first $1 \mathrm{~h}$ of the intestinal lipolysis with pancreatin (Fig. 1D). The intestinal phase of digestion is where chyme is exposed to highly surface-active bile salts (Macierzanka, Torcello-Gómez, Jungnickel, \& Maldonado-Valderrama, 2019). These physiological surfactants aid in effective intestinal lipolysis by emulsifying ingested lipids, and by solubilising and removing the lipolysis products from the oil-water interface. All these processes can lead to the reduction in the size of original TG droplets and in the formation of mixed micelles, composed of the lipolysis products, bile salts, as well as other polar lipids delivered with bile or ingested food (e.g., phospholipids). The resulting gastrointestinal digesta is usually a complex mixture of dispersed/ solubilised and surface-active lipids, including FFAs, DGs, MGs, bile salts 
and other lipids (e.g., phospholipids, cholesterols) (Armand et al., 1999; Fatouros, Walrand, Bergenstahl, \& Müllertz, 2009). In our study, these types of lipids were observed in digesta produced after $1-4 \mathrm{~h}$ of the gastrointestinal digestion (Fig. 1D).

The $\zeta$-potential values did not differ significantly $(P>.05)$ between the four gastrointestinal digesta samples (i.e., GI-1h, $-49.8 \pm 1.1 \mathrm{mV}$; GI-2h, $-48.6 \pm 2.1 \mathrm{mV}$; GI-3h, $-49.0 \pm 2.3 \mathrm{mV}$; GI-4h, $-49.2 \pm 1.8$ $\mathrm{mV}$ ), and were comparable to the results obtained for other postdigestion emulsions that had been digested in the presence of bile salts (Macierzanka et al., 2011, 2012). It was also noticed that the original size of lipid droplets in yogurt was reduced due to lipolysis and interfacial activity of bile salts (Fig. 1E). This behaviour is consistent with the results of other studies (Armand et al., 1999; Bonnaire et al., 2008). However, it was difficult to compare the mean particle size between the gastrointestinal digesta and the original yogurt, as the digesta samples revealed multimodal size distributions (Fig. 1E). Treating samples with SDS before measurement did not change the size profiles (data not shown), suggesting the polydispersity was not the effect of particle flocculation. The particle size distributions of the digesta samples seemed to be obscured to some extent by a particulate matter introduced to the intestine digestion mix with the pancreatin and the bile salt extract. These insoluble particles were likely to be cellular debris remaining in the preparations after extraction of pancreatic enzymes and bile salts from animal materials by the producer (SigmaAldrich). When measured separately, the pancreatin and the bile salt extract showed an existence of insoluble particles ranging in size from ca. $1 \mu \mathrm{m}$ to $>1000 \mu \mathrm{m}$, with most particles being well over $20 \mu \mathrm{m}$ in diameter (Fig. 1E). Those particles contributed to the volume size distributions of the digesta samples withdrawn during digestion. However, the majority of them were much larger than the particles of digested lipids and did not dominate the distribution profiles of digesta samples (Fig. 1E). This meant they could not greatly contribute to the overall number of particles, the major fraction of which was represented by considerably smaller lipid particles. The negligible contribution of the insoluble particulate matter that derived from pancreatin and bile extract was confirmed by converting the volume distributions of the four gastrointestinal digesta samples to number distributions (Fig. 1F). The gastrointestinal digesta was further used in the major part of the study looking at the effect of the type of small intestinal mucus on its penetrability to the post-digestion lipid particles.

\subsection{Diffusion of gastrointestinal digesta in the small intestinal mucus}

\subsubsection{Sieve-like barrier properties of mucus}

We have developed a simple optical cell that allowed for convenient and reproducible monitoring of interactions between mucus and colloidal dispersions. The cell was used to bring the liquid digesta samples into contact with the small intestinal mucus without compromising the integrity of the mucus gel. This way, the penetration of the mucus layer by the lipid particles undergoing Brownian motion in the digesta could be monitored immediately after the digesta and mucus were brought together (Fig. 2A,B), mimicking the passage of dispersed/ solubilised lipids from the small intestinal lumen into the mucus overlaying the intestinal epithelium. Fluorescent intensity profiles of stained lipids were generated from the time-lapse CLSM images (Fig. 2C) and used to assess the diffusion of lipid digesta in the mucus layer as explained in Section 2.4.

By applying this approach, we have initially evaluated an influence of the digestion time on the diffusion rate of digesta in mucus. The mucus scraped from the jejunal segments of the small intestine in adult pigs was chosen for experiments as this type of ex vivo mucus had previously been shown to produce relatively little individual variability regarding rheological properties (Macierzanka et al., 2011). It has also been shown, by multiple-particle tracking of $500 \mathrm{~nm}$ latex beads, that porcine mucus collected ex vivo maintains the same microstructural characteristics and permeability to particles as the native mucus overlaying the jejunal mucosa, even if the ex vivo mucus was subjected to freezing and thawing after collection (Macierzanka, Mackie, et al., 2019).

Fig. 3A shows the comparison of diffusion coefficients of the digesta samples obtained after 1, 2, 3 and $4 \mathrm{~h}$ of gastrointestinal digestion. For each mucus penetration time, there was a subtle inverse correlation between the mean diffusivity value and the digestion time. However, the correlations were not statistically significant $(P>.05)$ within the same penetration times, even during the first several minutes after the start of mucus penetration when the effect was most noticeable (Fig. 3A). This might have been due to the relatively small differences in the size distribution profiles between the four time-point digesta samples collected during the course of digestion (Fig. 1F). Much more profound was a progressive decrease in the apparent diffusion of digesta over the time of mucus penetration (Fig. 3A). This trend was consistent for all four types of gastrointestinal digesta. A significant drop in diffusion coefficient was observed during the first $30 \mathrm{~min}$ after the initial penetration of mucus, and then the diffusivity remained fairly constant until the end of experiment. The ratios of diffusion coefficients from $5 \mathrm{~min}$ to $90 \mathrm{~min}$ after the start of penetration into the mucus $\left(\mathrm{D}_{90} / \mathrm{D}_{5}\right)$ showed consistently for each digesta that there was a nearly $70 \%$ reduction of the initial diffusivity after $90 \mathrm{~min}$ (Fig. 3B). An explanation for this phenomenon may lie in the way the small intestinal mucus is organised at the microscale. The gel-forming MUC2 mucin oligomers are able to form a porous network in the mucus, which can limit movement only to particles not restricted by the mesh size. In murine jejunal mucus, an average pore size of $200-220 \mathrm{~nm}$ was found (Bajka, Rigby, Cross, Macierzanka, \& Mackie, 2015). However, the reported sizes ranged broadly, from $75 \mathrm{~nm}$ to approx. $500 \mathrm{~nm}$. Furthermore, the transport of particles can be affected by the spatial organisation of mucin microscale domains in the mucus. A hierarchical model of colloidal transport through the small intestinal mucus has been postulated by Round and co-workers (Round et al., 2012). It involves an existence of individual lamellae of MUC2 mucin network rather than a continuous threedimensional network of the mucin polymer. According to the model, the weak interactions between the lamellae allow for the passage of particles larger than the pores in lamellae as those particles are able to diffuse along transient channels between lamellae. Particles smaller than the pore size can traverse directly through the lamellae as long as they are not sterically trapped. More recently, Meldrum et al. (2018) reported on a similar mechanism of a network assembly of MUC2 mucin in which viscoelastic microscale domains of mucin oligomers were proposed to form via hydrogen bonding and $\mathrm{Ca}^{2+}$-mediated links. Individual domains were then assembled in a yield stress, gel-like fluid. In the previous studies on multiple-particle tracking in mucus (Bajka et al., 2015; Macierzanka et al., 2011, 2014), a broad diffusivity distribution was observed for non-mucoadhesive, monodisperse nano- and microbeads that were used to probe the microviscosity of the porcine small intestinal mucus. Those results confirmed a high degree of mucus heterogeneity and might also support the postulated hierarchical organisation of the mucus microstructure.

Taking into account these previous findings as well as the results of the present study (Fig. 3), the small intestinal mucus may be considered to act as a sieve to a polydisperse digesta through the network of channels and pores of various sizes. The concept of size filtering has been previously introduced for different types of mucus (Lieleg, Vladescu, \& Ribbeck, 2010); it assumes that particles smaller than mucus mesh size are allowed to pass while larger particles are rejected. The contrasting concept of interaction filtering is based on the strength of interaction between particles and the mucus polymer network, so the weakly interacting particles are not retained in the mucus and allowed to diffuse. In this study, the gastrointestinal digesta was produced in the presence of bile extract containing bile salts, which must have been responsible for the high negative charge of the digesta dispersions ( $\zeta$-potential ca. $-49 \mathrm{mV}$, see Section 3.1). The adsorption of anionic bile salts has been shown previously to hugely enhance the diffusivity of 


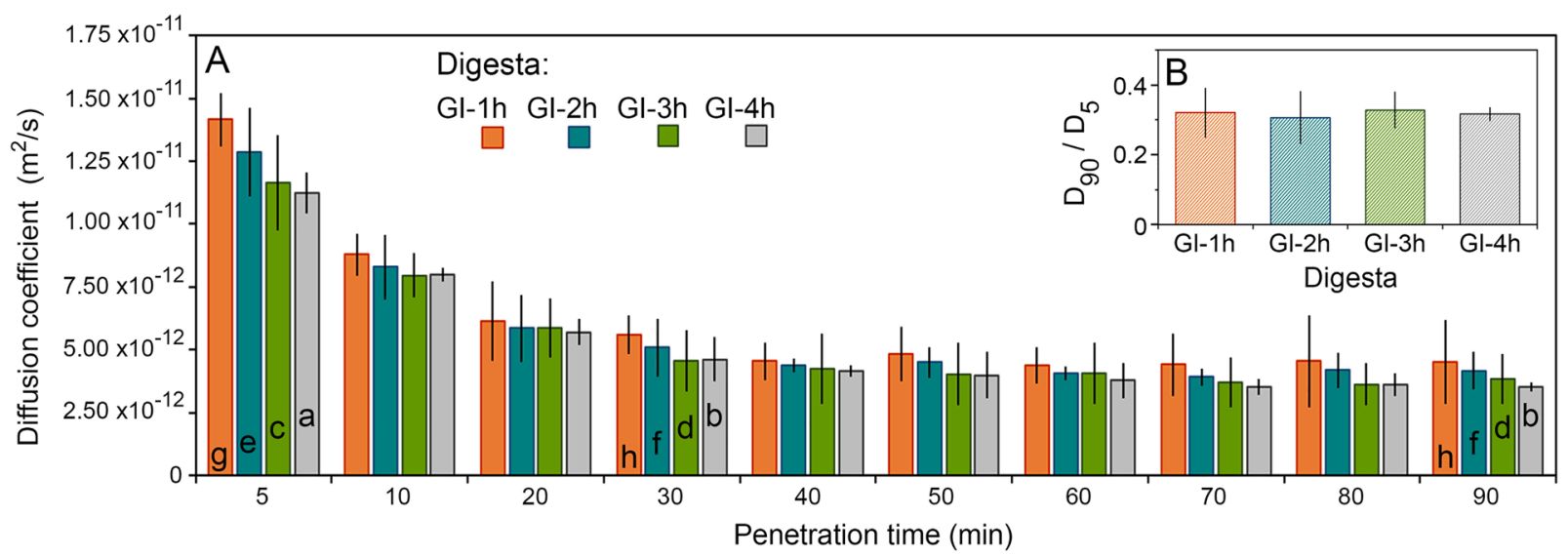

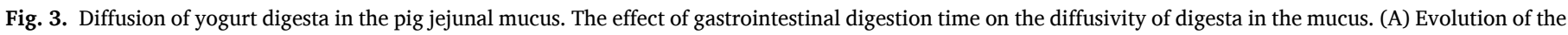

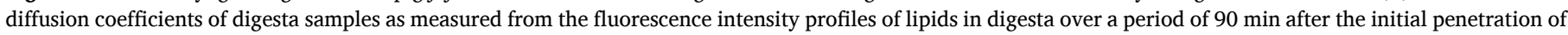

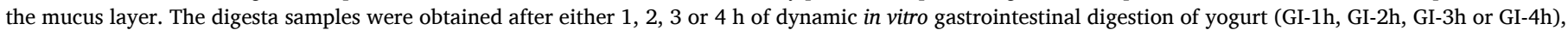

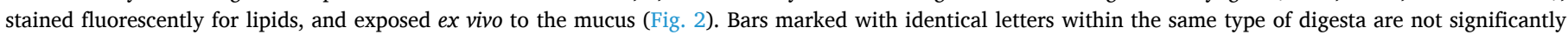

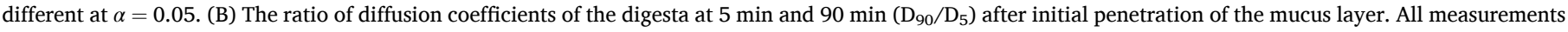
were conducted at $37 \pm 0.1{ }^{\circ} \mathrm{C}$. Mean $\pm \mathrm{SD}(\mathrm{n}=3)$.

particles in small intestinal mucus by strengthening their negative surface charge and thus preventing mucoadhesion (Macierzanka et al., 2011, 2012). Therefore, the size filtering mechanism seems to be the most likely explanation in the present study for the sieve-like behaviour of the mucus confronted with the yogurt digesta. It is plausible that the largest lipid particles in digesta were immobilised within a relatively short time after penetrating into the mucus layer, whereas smaller particles were able to diffuse deeper into the mucus. The former was suggested by an increase in red fluorescence in the boundary region of the mucus over the fluorescence recorded for digesta in the luminal space (Fig. 2C). Consequently, it was only the smallest particles that were likely to penetrate through the surface region of mucus clogged with the lipid droplets larger than the mucus mesh size (i.e., the size of channels and pores), and continued to diffuse freely in the mucus at a constant rate until the end of the penetration experiment $(90 \mathrm{~min}$, Fig. 3A). This may suggest that, under physiological conditions of the gut, lipolysis continues in the intestinal mucus after partially digested fat droplets leave the intestinal lumen and get entangled in the mucus. The diffusion through the mucus and towards the underlying epithelium would then only continue after they become gradually reduced to smaller droplets and/or particles of assembled lipolysis products due to enzymatic hydrolysis and assistance of the surface-active bile salts.

A similar clogging of intestinal mucus has been observed previously after the mucus was exposed to the soluble dietary fibre sodium alginate (Mackie, Macierzanka, et al., 2016). As a result, the apparent diffusivity of that high molecular weight polymer was reduced in the function of mucus penetration time, despite the lack of interaction between the mucin and the alginate. Local diffusivity of lipid digesta inside the small intestinal mucus matrix has been studied before (Mackie, Rigby, Harvey, $\&$ Bajka, 2016). However, our present report is the first time the sievelike behaviour of mucus has been shown to affect the transport rates of a complex, polydisperse mixture of post-digestion lipid particles during the penetration into the mucus layer from a simulated luminal space.

\subsubsection{Penetration of human and porcine mucus layer}

Having analysed the diffusion of various digesta samples in the pig jejunal mucus, we looked at how the permeation of digesta may be affected by the type of small intestinal mucus. The penetrability was compared between mucus samples obtained from the jejunum of adult pigs, and the ileum of adult pigs and humans. We also included jejunal mucus from 2 week old piglets in the study. This aimed to investigate the following, individual comparisons of mucus types: (i) age-specific (i.e., piglet vs. adult pig; both for jejunal mucus), (ii) intestinal location- specific (i.e., jejunal mucus vs. ileal mucus; both for adult pig), and (iii) species-specific (i.e., adult pig vs. adult human; both for ileal mucus). The yogurt digesta produced after $2 \mathrm{~h}$ of gastrointestinal digestion (GI-2h) was used for analysing penetrability of different types of mucus. As for the initial experiments shown in Figs. 2 and 3, mucus samples were exposed to the digesta at $37{ }^{\circ} \mathrm{C}$, and diffusion of fluorescently-labelled lipids into the mucus monitored in the function of time (Fig. 4).

The fluorescence profiles revealed a striking difference in penetration rates between the two jejunal types of mucus analysed (Fig. 4A). The piglet mucus was significantly more permeable to the diffusing digesta than the pig mucus, and after 5 min from the start of penetration the respective mean diffusion coefficients were $6.56 \times 10^{-11} \mathrm{~m}^{2} \mathrm{~s}^{-1}$ and $1.29 \times 10^{-11} \mathrm{~m}^{2} \mathrm{~s}^{-1}(P<.05$, Fig. 4B). This indicates the piglet mucus presents a less effective barrier to passively diffusing lipid particles. The microstructural organisation of the pig and the piglet jejunal mucus has been compared previously, using direct tracking of the movement of $500 \mathrm{~nm}$ latex beads in mucus (Macierzanka et al., 2014). The two mucus secretions used in that study were pre-treated with DNase in order to reduce the impact of extracellular DNA on the viscosity experienced by the probe particles. The study revealed a substantial difference in the diffusivity of beads, which was largely due to contrasting ways the mucin matrix was organised between the two mucus types. In the mucus of fully-grown pigs, the mucin produced a coherent porous network, whereas in the piglet mucus the network was more heterogeneous and fragmented. It consisted of large aggregates of mucin polymer surrounded by regions with lower local concentrations of the glycoprotein. The most rapid diffusion of the tracer particles was observed in those regions. According to the same report, the piglet mucus also contained approx. $40 \%$ less extracellular DNA than the pig mucus. The differences in both the mucin organisation and the DNA concentration were suggested to be caused by disparities in the distribution of mucin-producing goblet cells and in the epithelial cell turnover during neonatal development compared to adulthood. Because of this, the mean microviscosity experienced by the latex beads diffusing in the piglet mucus was roughly half the value recorded for the pig counterpart (Macierzanka et al., 2014). The impact of developmental age on differences in chemical composition, structural properties and permeability to particles of small intestinal mucus was studied recently in rats (Lock et al., 2020). The gut immaturity was suggested to be responsible for significantly lower concentrations of mucin and DNA in the ileal mucus of 5 day old rat pups relative to 21 day old rats. Particle tracking experiments, using 200 nm PEG-, carboxyl- and amine-modified polystyrene 

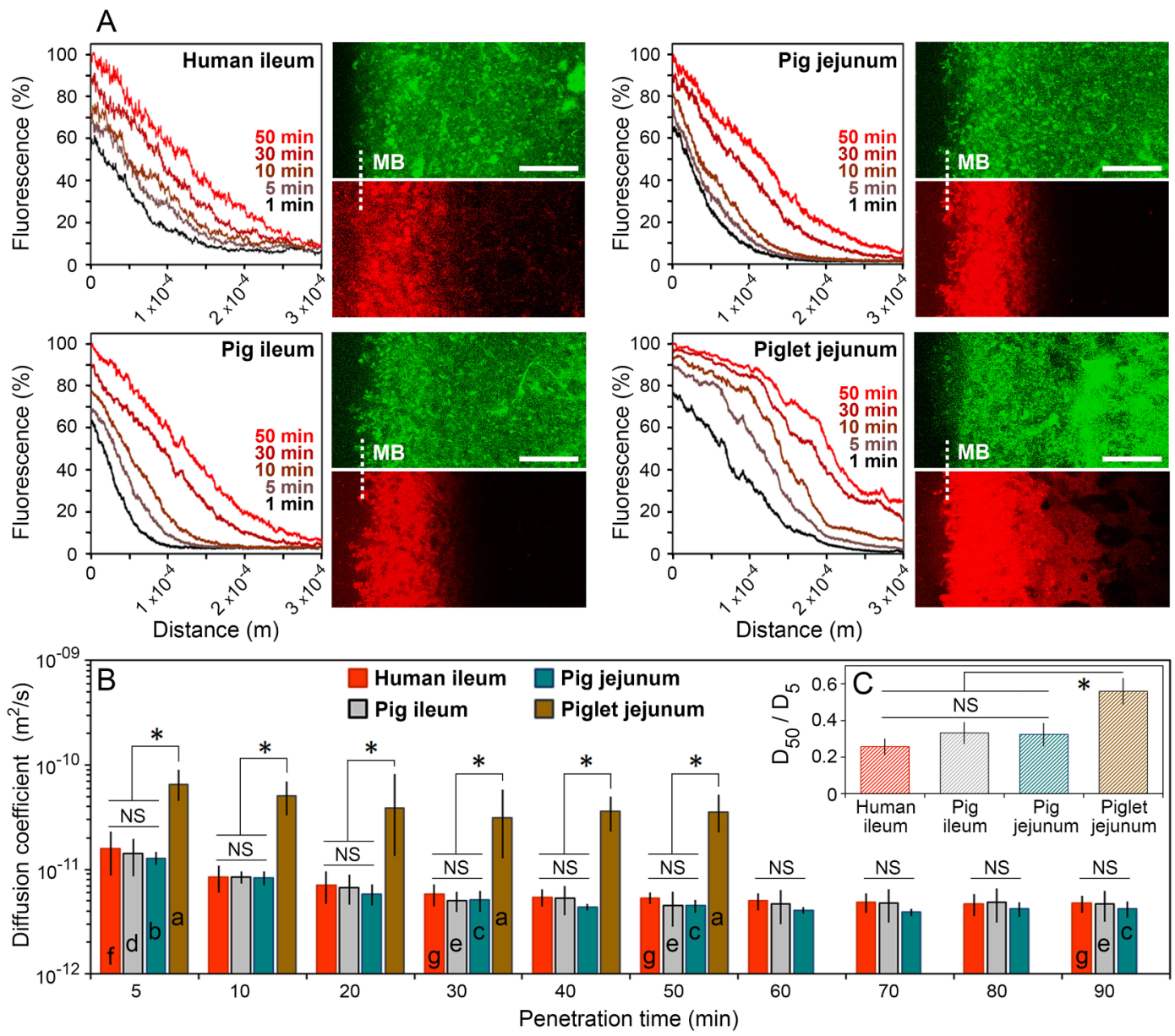

Fig. 4. Comparison of the penetration rates of gastrointestinal yogurt digesta into the human and porcine small intestinal mucus. The digesta was obtained after $2 \mathrm{~h}$ of dynamic in vitro gastrointestinal digestion of yogurt (GI-2h) and exposed ex vivo to the mucus collected from the human ileum, the pig ileum, the pig jejunum, and the piglet jejunum. (A) Representative fluorescence intensity profiles (normal to the mucus boundary) of digesta stained for lipids in the function of the distance of penetration into the mucus. The fluorescence profiles were recorded at 1, 5, 10, 30 and $50 \mathrm{~min}$ after the initial penetration of the mucus layer. Each florescence graph is accompanied by CLSM images showing the mucus boundary (MB; mucus is shown in green channel) and the extent of digesta penetration (red channel) into mucus after $10 \mathrm{~min}$. The scale bars correspond to $100 \mu \mathrm{m}$. (B) Evolution of the diffusion coefficient of the yogurt digesta in the four mucus types over a period of up to 90 min after the initial penetration of mucus, as measured from the fluorescence intensity profiles of lipids in digesta. Bars marked with identical letters within the same type of mucus are not significantly different at $\alpha=0.05$. (C) The ratio of diffusion coefficients of the digesta at $5 \mathrm{~min}$ and $50 \mathrm{~min}\left(\mathrm{D}_{50} / \mathrm{D}_{5}\right)$ after initial penetration of the mucus layer. All measurements were conducted at $37 \pm 0.1^{\circ} \mathrm{C}$. Mean $\pm \mathrm{SD}(\mathrm{n}=3-5) ;{ }^{*} P<.05$; NS, not significant $(P>.05)$. (For interpretation of the references to colour in this figure legend, the reader is referred to the web version of this article.)

particles, showed the mucus from early developmental age rats (5 day old) was substantially more permeable to diffusing particles compared to 21 day old rats. The mucus of the former age group was also significantly more penetrable to flagellated bacteria (E. coli), suggesting immaturity may contribute to enhanced exposure of the intestinal epithelium to microbes.

Since the structural barrier properties of mucus appear to develop during infancy, it is not surprising that in the present study we observed a higher diffusivity of digesta in the 2 week old piglet mucus than in the adult pig mucus. The broad size distribution of lipid particles in the digesta (Fig. 1E) does not allow for using them to probe the microviscosity of mucus, as the diffusion of an individual particle greatly depends on its diameter (Lai et al., 2010). However, results of the timelapse measurements with digesta produced from a real dairy product may provide new insights into how the permeability of jejunal mucus to lipids can change postneonatally. Because of the relatively fast penetration of digesta into the piglet mucus, the experiment was terminated after $50 \mathrm{~min}$ from the initial penetration of this type of mucus (Fig. 4B). Although the diffusivity of digesta was reduced progressively over the first $30 \mathrm{~min}$ in the piglet mucus, the difference between the diffusion coefficients after $5 \mathrm{~min}$ and $30 \mathrm{~min}$ was not significant $(P>.05)$. This suggests the channels and pores in the mucus matrix were not substantially clogged with large lipid particles, and allowed fast transport. This also supports the previous findings of a loose and easy-to-penetrate structure of neonatal mucus (Lock et al., 2020; Macierzanka et al., 2014). The diffusivity in piglet mucus remained unchanged for the remaining $20 \mathrm{~min}$. This is in contrast to what was observed for the pig jejunal mucus. There was a significant drop in the rate of digesta diffusion measured between $5 \mathrm{~min}$ and $30 \mathrm{~min}(P<.05)$ from the start of mucus penetration. The diffusion coefficient remained constant after 30 min and until the end of experiment. The difference in penetrability of the two types of jejunal mucus was further emphasised by comparing the ratios of diffusion coefficients from $5 \mathrm{~min}$ to $50 \mathrm{~min}\left(\mathrm{D}_{50} / \mathrm{D}_{5}\right.$, Fig. $\left.4 \mathrm{C}\right)$. For the piglet mucus, the ratio was almost twice as high as for the pig mucus, meaning that the apparent diffusivity of digesta was reduced far more substantially by the pig mucus.

The above suggest that the transmucus transport of lipids in a neonatal small intestine might be much faster than in a mature gut. It can potentially involve the arrival of lipid droplets/particles with a large spectrum of sizes in close proximity to the epithelium, which may enhance the rate of intestinal absorption of lipolysis products that are eventually released from hydrolysed fat droplets. This, however, can be 
limited by low activity/concentration of pancreatic lipase in the neonatal small intestine, as reported for the human pre-term and fullterm infants relative to adults (Bourlieu et al., 2014). Further studies would be required to assess the combined impact of mucus structure and digestion conditions on the rate of intestinal lipid absorption.

Comparing the permeability of mucus from different segments of the small intestine has not attracted much scientific attention so far despite the fact that the mucosal architecture varies longitudinally as the villi length decreases from the duodenum to the ileum, which may affect the structural properties of the mucus layer. In our study, the sieve-like barrier behaviour, characteristic of the pig jejunal mucus, was also observed for the ileal mucus obtained from fully-grown pigs. The time evolution in the fluorescence intensity profiles of digesta, and thus in the diffusivity observed in the ileal mucus mirrored that recorded for the jejunal mucus (Fig. 4A,B). The $\mathrm{D}_{50} / \mathrm{D}_{5}$ ratios for both types of pig mucus were very similar, and showed that there was an almost $70 \%$ reduction in the apparent diffusion of digesta after 50 min of mucus penetration regardless of the original, anatomical location of the mucus (Fig. 4C). The ratios did not change significantly after extending the penetration to 90 min (Supplementary Fig. S3). The reduction of the diffusion rate in the function of penetration time, over the initial $50 \mathrm{~min}$, meant that for both types of mucus some lipid particles could penetrate as deep as $100-150 \mu \mathrm{m}$ into the mucus layer during the first 5-10 min, whereas the penetration depth could only increase to ca. $300 \mu \mathrm{m}$ after $50 \mathrm{~min}$ (Fig. 4A). The fact that the diffusion coefficients were very similar for both types of mucus (Fig. 4B) suggests that in vivo the transmucosal transport times might depend on variations in the thickness of the mucus layer between the jejunum and the ileum, rather than on differences in mucus microstructure. However, the effect of varying thickness on transport times might be difficult to account for. To our knowledge, there are no studies looking at how these variations might look in humans. In rats, the ileal mucus layer was reported to be significantly thicker than the duodenal and jejunal mucus gel layers $(480 \pm 47 \mu \mathrm{m}$, $170 \pm 38 \mu \mathrm{m}$ and $123 \pm 4 \mu \mathrm{m}$, respectively, (Atuma, Strugala, Allen, \& Holm, 2001)). It was also observed that the mean mucus thickness can be reduced approx. 7 -fold in the rat ileum and even $>20$-fold in the jejunum after feeding relative to the animals fasted for $48 \mathrm{~h}$ (Szentkuti \& Lorenz, 1995). However, in the mouse, no substantial difference was found between the thickness of jejunal and ileal mucus (Ermund, Schütte, Johansson, Gustafsson, \& Hansson, 2013). There were no significant differences observed for the mean pore size of mucus and the size distribution profiles between the two intestinal segments either (Bajka et al., 2015). The latter mouse study supports our finding of the very comparable penetrability of jejunal and ileal mucus to digesta (Fig. 4B), and implies a similar lack of difference in microstructural organisation of mucus in proximal and distal regions of the pig small intestine.

Importantly, we have also looked at how the human mucus was penetrated by the lipid particles of digesta. The results showed a very similar behaviour of the human ileal mucus and the pig jejunal and ileal mucus (Fig. 4B). Analogically to the pig mucus, the diffusion coefficient of digesta decreased significantly $(P<.05)$ over the first $30 \mathrm{~min}$ after bringing the digesta into contact with human mucus, and remained largely unchanged after that time at ca. $5 \times 10^{-12} \mathrm{~m}^{2} \mathrm{~s}^{-1}$. There was no significant difference in how the diffusivity evolved in time between the human mucus and the pig mucus, which has been shown by comparing the actual values of diffusion coefficient (Fig. 4B) as well as the ratios of diffusivities at various stages of mucus penetration (Fig. 4C, Supplementary Fig. S3). All these results imply a very similar microstructural organisation of the adult human and pig small intestinal mucus with regard to penetrability to polydisperse colloidal particles. These data bring about the proof for the human-relevance of adult pig small intestinal mucus in terms of selective barrier properties to post-digestion luminal lipids.

\section{Conclusions}

We compared ex vivo the penetrability of several types of small intestinal mucus to digesta obtained after simulated dynamic gastrointestinal digestion of yogurt. The overall apparent diffusivity of digesta in adult pig mucus decreased significantly during the first $30 \mathrm{~min}$ of penetration, suggesting a sieve-like response of the mucus matrix to the post-digestion lipid particles varying in size. The rate of digesta diffusion in the mucus of 2 week old piglets was several times faster. This suggests that neonatal mucus is a less effective barrier to passively diffusing lipid particles relative to adult mucus.

Most importantly, we showed that the evolution in penetrability of the adult human small intestinal mucus to diffusing lipids was analogous to the penetration profiles of the mucus obtained from adult pigs. To our knowledge, it is the first time such analogies have been reported for the transport of gastrointestinal digesta. This validates the use of small intestinal mucus from fully-grown pigs as a human-relevant substitute in studies focusing on the transmucus transports of molecules and complex colloidal dispersions (e.g., nutrients/bioactives, digested foods, orallyadministrated drug delivery systems) under simulated conditions of the adult human small intestine. The close resemblance in penetrability to diffusing entities of the adult pig mucus and the adult human mucus suggests that some analogy might also be expected between the examined piglet mucus and the mucus of human infants, which was not studied. However, confirming any such similarity would certainly require further studies that, for obvious ethical reasons, might be problematic.

\section{CRediT authorship contribution statement}

Adam Macierzanka: Conceptualization, Methodology, Validation, Formal analysis, Investigation, Resources, Data curation, Writing original draft, Writing - review \& editing, Visualization, Supervision, Project administration, Funding acquisition. Olivia Ménard: Validation, Investigation, Data curation, Writing - review \& editing. Didier Dupont: Methodology, Resources, Writing - review \& editing. Krzysztof Gutkowski: Resources, Writing - review \& editing. Robert Staroń: Methodology, Resources, Writing - review \& editing. Lukasz Krupa: Methodology, Validation, Formal analysis, Investigation, Resources, Data curation, Writing - original draft, Writing - review \& editing, Visualization.

\section{Declaration of Competing Interest}

The authors declare that they have no known competing financial interests or personal relationships that could have appeared to influence the work reported in this paper.

\section{Acknowledgements}

The work was supported by the Polish National Agency for Academic Exchange NAWA through a Bekker Programme grant (PPN/BEK/2018/ 1/00073). The work was co-funded by the BBSRC, UK (research grant BBS/E/F/00044424). A.M., O.M. and D.D. are participants of the INFOGEST international network on Food Digestion. The funding sources had no role in study design; in the collection, analysis and interpretation of data; in preparation of the manuscript; or in the decision to submit the article for publication.

\section{Appendix A. Supplementary material}

Supplementary data to this article can be found online at https://doi. org/10.1016/j.foodres.2020.109752. 


\section{References}

Armand, M., Pasquier, B., André, M., Borel, P., Senft, M., Peyrot, J., ... Lairon, D. (1999) Digestion and absorption of 2 fat emulsions with different droplet sizes in the human digestive tract. American Journal of Clinical Nutrition, 70(6), 1096-1106. https://doi. org/10.1093/ajcn/70.6.1096.

Atuma, C., Strugala, V., Allen, A., \& Holm, L. (2001). The adherent gastrointestinal mucus gel layer: Thickness and physical state in vivo. American Journal of PhysiologyGastrointestinal and Liver Physiology, 280(5), G922-G929. https://doi.org/10.1152/ ajpgi.2001.280.5.G922.

Bajka, B. H., Rigby, N. M., Cross, K. L., Macierzanka, A., \& Mackie, A. R. (2015). The influence of small intestinal mucus structure on particle transport ex vivo. Colloids and Surfaces B: Biointerfaces, 135, 73-80. https://doi.org/10.1016/j. colsurfb.2015.07.038.

Bonnaire, L., Sandra, S., Helgason, T., Decker, E. A., Weiss, J., \& McClements, D. J. (2008). Influence of lipid physical state on the in vitro digestibility of emulsified lipids. Journal of Agricultural and Food Chemistry, 56(10), 3791-3797. https://doi. org/10.1021/jf800159e.

Böttger, F., Dupont, D., Marcinkowska, D., Bajka, B., Mackie, A., \& Macierzanka, A. (2019). Which casein in sodium caseinate is most resistant to in vitro digestion? Effect of emulsification and enzymatic structuring. Food Hydrocolloids, 88, 114-118. https://doi.org/10.1016/j.foodhyd.2018.09.042.

Bourlieu, C., Ménard, O., Bouzerzour, K., Mandalari, G., Macierzanka, A., Mackie, A. R. \& Dupont, D. (2014). Specificity of infant digestive conditions: some clues for developing relevant in vitro models. Critical Reviews in Food Science and Nutrition, 54 (11), 1427-1457. https://doi.org/10.1080/10408398.2011.640757.

Bucci, C., Rotondano, G., Hassan, C., Rea, M., Bianco, M. A., Cipolletta, L., ... Marmo, R. (2014). Optimal bowel cleansing for colonoscopy: Split the dose! A series of metaanalyses of controlled studies. Gastrointestinal Endoscopy, 80(4), 566-576.e2. https://doi.org/10.1016/j.gie.2014.05.320.

Cone, R. A. (2009). Barrier properties of mucus. Advanced Drug Delivery Reviews, 61(2), 75-85. https://doi.org/10.1016/j.addr.2008.09.008.

Corfield, A. P., Carroll, D., Myerscough, N., \& Probert, C. S. (2001). Mucins in the gastrointestinal tract in health and disease. Frontiers in Bioscience: A Journal and Virtual Library, 6(1), D1321-57. https://doi.org/10.2741/corfield.

Elashoff, J. D., Reedy, T. J., \& Meyer, J. H. (1982). Analysis of gastric emptying data. Gastroenterology, 83(6), 1306-1312. https://doi.org/10.1016/S0016-5085(82) 80145-5.

Ermund, A., Schütte, A., Johansson, M. E. V., Gustafsson, J. K., \& Hansson, G. C. (2013). Studies of mucus in mouse stomach, small intestine, and colon. I. Gastrointestinal mucus layers have different properties depending on location as well as over the Peyer's patches. American Journal of Physiology-Gastrointestinal and Liver Physiology, 305(5), G341-G347. https://doi.org/10.1152/ajpgi.00046.2013.

Fatouros, D. G., Walrand, I., Bergenstahl, B., \& Müllertz, A. (2009). Colloidal structures in media simulating intestinal fed state conditions with and without lipolysis products. Pharmaceutical Research, 26(2), 361-374. https://doi.org/10.1007/ s11095-008-9750-9.

Gonzales, G. B., Smagghe, G., Mackie, A., Grootaert, C., Bajka, B., Rigby, N., ... Van Camp, J. (2015). Use of metabolomics and fluorescence recovery after photobleaching to study the bioavailability and intestinal mucus diffusion of polyphenols from cauliflower waste. Journal of Functional Foods, 16, 403-413. https://doi.org/10.1016/j.jff.2015.04.031.

Johansson, M. E. V., Sjövall, H., \& Hansson, G. C. (2013). The gastrointestinal mucus system in health and disease. Nature Reviews Gastroenterology and Hepatology, 10(6), 352-361. https://doi.org/10.1038/nrgastro.2013.35.

Lai, E. J., Calderwood, A. H., Doros, G., Fix, O. K., \& Jacobson, B. C. (2009). The Boston bowel preparation scale: A valid and reliable instrument for colonoscopy-oriented research. Gastrointestinal Endoscopy, 69(3 Suppl.), 620-625. https://doi.org/ 10.1016/j.gie.2008.05.057.

Lai, S. K., Wang, Y.-Y., Wirtz, D., \& Hanes, J. (2009). Micro- and macrorheology of mucus. Advanced Drug Delivery Reviews, 61(2), 86-100. https://doi.org/10.1016/j. addr.2008.09.012.

Lai, S. K., Wang, Y. Y., Hida, K., Cone, R., \& Hanes, J. (2010). Nanoparticles reveal that human cervicovaginal mucus is riddled with pores larger than viruses. Proceedings of the National Academy of Sciences of the United States of America, 107(2), 598-603. https://doi.org/10.1073/pnas.0911748107.

Lieleg, O., Vladescu, I., \& Ribbeck, K. (2010). Characterization of particle translocation through mucin hydrogels. Biophysical Journal, 98(9), 1782-1789. https://doi.org/ 10.1016/j.bpj.2010.01.012.

Lock, J. Y., Carlson, T. L., Yu, Y., Lu, J., Claud, E. C., \& Carrier, R. L. (2020). Impact of developmental age, necrotizing enterocolitis associated stress, and oral therapeutic intervention on mucus barrier properties. Scientific Reports, 10(1), 6692. https://doi. org/10.1038/s41598-020-63593-5.

Macierzanka, A., Böttger, F., Rigby, N. M., Lille, M., Poutanen, K., Mills, E. N. C., \& Mackie, A. R. (2012). Enzymatically structured emulsions in simulated gastrointestinal environment: Impact on interfacial proteolysis and diffusion in intestinal mucus. Langmuir, 28(50), 17349-17362. https://doi.org/10.1021/ la302194q.
Macierzanka, A., Mackie, A. R., Bajka, B. H., Rigby, N. M., Nau, F., \& Dupont, D. (2014). Transport of particles in intestinal mucus under simulated infant and adult physiological conditions: Impact of mucus structure and extracellular DNA. PLOS ONE, 9(4), Article e95274. https://doi.org/10.1371/journal.pone.0095274.

Macierzanka, A., Mackie, A. R., \& Krupa, L. (2019). Permeability of the small intestinal mucus for physiologically relevant studies: Impact of mucus location and ex vivo treatment. Scientific Reports, 9(1), 17516. https://doi.org/10.1038/s41598-01953933-5.

Macierzanka, A., Rigby, N. M., Corfield, A. P., Wellner, N., Böttger, F., Mills, E. N. C., \& Mackie, A. R. (2011). Adsorption of bile salts to particles allows penetration of intestinal mucus. Soft Matter, 7(18), 8077-8084. https://doi.org/10.1039/ c1sm05888f.

Macierzanka, A., Torcello-Gómez, A., Jungnickel, C., \& Maldonado-Valderrama, J. (2019). Bile salts in digestion and transport of lipids. Advances in Colloid and Interface Science, 274, Article 102045. https://doi.org/10.1016/j.cis.2019.102045.

Mackie, A. R., Macierzanka, A., Aarak, K., Rigby, N. M., Parker, R., Channel, G. A., Bajka, B. H. (2016). Sodium alginate decreases the permeability of intestinal mucus. Food Hydrocolloids, 52, 749-755. https://doi.org/10.1016/j.foodhyd.2015.08.004.

Mackie, A., Rigby, N., Harvey, P., \& Bajka, B. (2016). Increasing dietary oat fibre decreases the permeability of intestinal mucus. Journal of Functional Foods, 26, 418-427. https://doi.org/10.1016/j.jff.2016.08.018.

Maisel, K., Ensign, L., Reddy, M., Cone, R., \& Hanes, J. (2015). Effect of surface chemistry on nanoparticle interaction with gastrointestinal mucus and distribution in the gastrointestinal tract following oral and rectal administration in the mouse. Journal of Controlled Release, 197, 48-57. https://doi.org/10.1016/j.jconrel.2014.10.026.

Malagelada, J.-R., Longstreth, G. F., Summerskill, W. H. J., \& Go, V. L. W. (1976). Measurement of gastric functions during digestion of ordinary solid meals in man. Gastroenterology, 70(2), 203-210. https://doi.org/10.1016/S0016-5085(76)80010-

Meldrum, O. W., Yakubov, G. E., Bonilla, M. R., Deshmukh, O., McGuckin, M. A., \& Gidley, M. J. (2018). Mucin gel assembly is controlled by a collective action of nonmucin proteins, disulfide bridges, Ca2+-mediated links, and hydrogen bonding. Scientific Reports, 8(1), 5802. https://doi.org/10.1038/s41598-018-24223-3.

Ménard, O., Bourlieu, C., De Oliveira, S. C., Dellarosa, N., Laghi, L., Carrière, F., \& Deglaire, A. (2018). A first step towards a consensus static in vitro model for simulating full-term infant digestion. Food Chemistry, 240(March), 338-345. https:// doi.org/10.1016/j.foodchem.2017.07.145.

Ménard, O., Cattenoz, T., Guillemin, H., Souchon, I., Deglaire, A., Dupont, D., \& Picque, D. (2014). Validation of a new in vitro dynamic system to simulate infant digestion. Food Chemistry, 145, 1039-1045. https://doi.org/10.1016/j. foodchem.2013.09.036.

Ménard, O., Famelart, M.-H., Deglaire, A., Le Gouar, Y., Guérin, S., Malbert, C.-H., \& Dupont, D. (2018). Gastric emptying and dynamic in vitro digestion of drinkable yogurts: Effect of viscosity and composition. Nutrients, 10(9), 1308. https://doi.org/ 10.3390/nu10091308.

Meral, M., Bengi, G., Kayahan, H., Akarsu, M., Soytürk, M., Topalak, Ö., ... Sağol, Ö. (2018). Is ileocecal valve intubation essential for routine colonoscopic examination? European Journal of Gastroenterology \& Hepatology, 30(4), 432-437. https://doi.org/ 10.1097/MEG.0000000000001065.

Minekus, M., Alminger, M., Alvito, P., Ballance, S., Bohn, T., Bourlieu, C., ... Brodkorb, A. (2014). A standardised static in vitro digestion method suitable for food-an international consensus. Food and Function, 5(6), 1113-1124. https://doi.org/ 10.1039/c3fo60702j.

Minekus, M., Marteau, P., Havenaar, R., \& Huisintveld, J. H. J. (1995). A multicompartmental dynamic computer-controlled model simulating the stomach and small intestine. Atla-Alternatives to Laboratory Animals, 23(2), 197-209.

Rioux, L. E., \& Turgeon, S. L. (2012). The ratio of casein to whey protein impacts yogurt digestion in vitro. Food Digestion, 3(1-3), 25-35. https://doi.org/10.1007/s13228012-0023-z.

Round, A. N., Rigby, N. M., Garcia De La Torre, A., Macierzanka, A., Mills, E. N. C., \& Mackie, A. R. (2012). Lamellar structures of MUC2-rich mucin: A potential role in governing the barrier and lubricating functions of intestinal mucus. Biomacromolecules, 13(10), 3253-3261. https://doi.org/10.1021/bm301024x.

Seo, E. H., Kim, T. O., Park, M. J., Joo, H. R., Heo, N. Y., Park, J., ... Moon, Y. S. (2012). Optimal preparation-to-colonoscopy interval in split-dose PEG bowel preparation determines satisfactory bowel preparation quality: An observational prospective study. Gastrointestinal Endoscopy, 75(3), 583-590. https://doi.org/10.1016/j. gie.2011.09.029.

Szentkuti, L., \& Lorenz, K. (1995). The thickness of the mucus layer in different segments of the rat intestine. Histochemical Journal, 27(6), 466-472. https://doi.org/10.1007/ bf00173712.

Yildiz, H. M., McKelvey, C. A., Marsac, P. J., \& Carrier, R. L. (2015). Size selectivity of intestinal mucus to diffusing particulates is dependent on surface chemistry and exposure to lipids. Journal of Drug Targeting, 23(7-8), 768-774. https://doi.org/ 10.3109/1061186X.2015.1086359.

Zhang, Q., Widmer, G., \& Tzipori, S. (2013). A pig model of the human gastrointestinal tract. Gut Microbes, 4(3), 193-200. https://doi.org/10.4161/gmic.23867. 